\title{
Sociologia e abordagem sociológica em A Estrutura das Revoluções Científicas
}

\section{Sociology and sociological approach in The Structure of Scientific Revolutions}

\author{
Paulo Pirozelli \\ Pós-doutorando no Instituto de Estudos Avançados, USP \\ paulo.pirozelli.silva@usp.br
}

\section{Resumo}

O objetivo deste trabalho é compreender o papel e a relevância da sociologia da ciência para as ideias desenvolvidas por Thomas Kuhn em $A$ Estrutura das Revoluçôes Científicas. No artigo, argumento que a Estrutura oferece uma explicação sociológica para aspectos fundamentais do desenvolvimento científico, ainda que as relações entre as ideias propostas por Kuhn e a sociologia da ciência sejam pouco discutidas pelo autor. $\mathrm{O}$ caráter sociológico da abordagem de Kuhn na Estrutura aparece de duas formas. Em primeiro lugar, o padrão de desenvolvimento da ciência é explicado por ele por meio das formas de organização e disposições comportamentais dos cientistas. Em segundo lugar, sua explicação da formação de consenso depende de uma compreensão da ciência como uma atividade realizada por uma comunidade de cientistas com avaliações divergentes.

Palavras-chave: Thomas Kuhn; Sociologia da Ciência; Formação de consenso; Escolha de teorias.

\section{Abstract}

The aim of this paper is to understand the role and relevance of the sociology of science to the ideas developed by Thomas Kuhn in The Structure of Scientific Revolutions. In this article, I argue that Structure offers a sociological explanation for fundamental aspects of scientific development, although the relationships between the ideas proposed by Kuhn and the sociology of science are not extensively discussed by the author. The sociological character of Kuhn's approach in Structure appears in two ways. First, the pattern of scientific development is explained by Kuhn through the forms of organization and behavioral dispositions of scientists. Second, his explanation of consensus formation depends on an understanding of science as an activity carried out by a community of scientists with divergent assessments.

Keywords: Thomas Kuhn; Sociology of Science; Consensus Formation; Theory Choice. 


\section{Introdução}

Publicada em 1962, A Estrutura das Revoluções Científicas (doravante, Estrutura), de Thomas Kuhn, alterou profundamente o modo como até então se concebia a ciência e seu progresso ao longo do tempo. De acordo com Kuhn, o desenvolvimento histórico das ciências naturais caracterizar-se-ia por longos períodos de estabilidade - marcados por incrementos cumulativos ao conhecimento prévio - seguidos de alterações radicais nos compromissos compartilhados - resultantes da aceitação de novos modelos científicos. No livro, Kuhn analisava ainda os mecanismos que explicariam o surgimento e transformação das tradições de pesquisa, que davam à ciência seu caráter não linear.

O impacto da Estrutura foi enorme, e se estendeu pelos mais diversos campos. Em pouco tempo, conceitos como "paradigma", "ciência normal" e "incomensurabilidade" haviam se difundido para além das fronteiras da filosofia da ciência, adentrando a linguagem do senso comum (Abbott, 2016). Curiosamente, foi dentro da própria filosofia da ciência que as ideias expostas no livro foram recebidas de maneira mais crítica, como indicam os trabalhos de Scheffler (1982) e Shapere (1964), ou os artigos encontrados em Lakatos \& Musgrave (1970). Para a filosofia da ciência da época, a abordagem da Estrutura parecia violar frontalmente uma série de princípios metodológicos então amplamente aceitos; em especial, ao aproximar a filosofia das ciências empíricas, tais como a psicologia e a sociologia da ciência. Contrariamente à metodologia então dominante, a abordagem de Kuhn possuía um forte viés naturalista, incorporando conceitos, teorias e evidências de diferentes áreas, a fim de explicar o processo de produção de conhecimento e a natureza da atividade científica (Bird, 2002; Pirozelli, 2020).

A aproximação da filosofia com as ciências empíricas, presente na Estrutura, acabou por suscitar uma aproximação na direção contrária. Assim como se mostrava devedora de outras disciplinas, a Estrutura se tornou ela mesma objeto de estudo e de análise em vários desses campos. Casos emblemáticos foram a psicologia, 
especialmente na década de 1960, e a história da ciência (ver, respectivamente, Kaiser, 2016; Shapin, 1992). ${ }^{1}$

Dentre todas as disciplinas nas quais as ideias da Estrutura foram lidas e debatidas, foi provavelmente a sociologia da ciência aquela em que sua influência se deu de maneira mais profunda e duradoura. Vista por muitos como responsável por estabelecer os fundamentos teóricos para a análise sociológica da ciência, a Estrutura teve impacto particularmente relevante nos estudos da ciência (science studies) e na sociologia do conhecimento científico (p. ex., Barnes \& Bloor, 1982; Barnes et al., 1996). Mesmo na sociologia da ciência mainstream seu impacto continuou a ser sentido nas décadas que se seguiram à sua publicação (Cole \& Harriet, 2017).

Apesar de seu papel central na constituição da sociologia da ciência como disciplina e de sua centralidade para as discussões teóricas na área, nem sempre é fácil compreender o lugar exato da sociologia no interior da Estrutura. Se, por um lado, não é possível encontrar aí qualquer discussão mais detalhada sobre o papel metodológico da sociologia (muito diferente do papel reservado à história da ciência, por exemplo²), não faltaram interpretações feitas por filósofos e sociólogos sobre esse tema (e, segundo Kuhn (1992), quase sempre distorcidas e exageradas). A natureza transdisciplinar da abordagem de Kuhn e o estilo sucinto da publicação acrescentam ainda mais dificuldades para a tentativa de compreensão do lugar da sociologia no esquema explicativo elaborado por ele.

Mas qual é, afinal, o lugar e o papel da sociologia na Estrutura? Nesse artigo, defendo que a sociologia - na verdade, uma abordagem sociológica desempenha uma função central no modelo elaborado por Kuhn. As considerações sociológicas têm, para ele, a função de explicar como a ciência se desenvolve ao

\footnotetext{
1 São vários os fatores que explicam a ampla recepção do livro: sua análise aparentemente iconoclasta do conhecimento científico, numa época em que a ciência atingia um grau inédito de relevância na sociedade; o padrão simples e sistemático de desenvolvimento científico que apresentava; a escrita acessível e sem o uso de jargão acadêmico elaborado; um conjunto de ferramentas originais para analisar a ciência em geral; a forte interdisciplinaridade do livro; as relações pessoais e profissionais cultivadas por Kuhn; entre outros. Para uma análise histórica dos fatores que levaram ao sucesso da Estrutura para além de sua audiência original, ver Gavroglu (2016).

${ }^{2} \mathrm{O}$ que não significa que não haja também interpretações divergentes sobre a relação entre história e filosofia na obra de Kuhn. Ver, por exemplo, Mladenović (2007).
} 
longo do tempo, em contraposição à função eminentemente descritiva ocupada pela história. $^{3}$

A primeira seção deste artigo faz uma análise da relação de Kuhn com a sociologia, prestando especial atenção à Estrutura. Como ficará claro, as discussões explícitas sobre o papel da sociologia na Estrutura (assim como no restante da obra de Kuhn) mostram-se bastante escassas.

O que procuro argumentar em seguida é que podemos, ainda assim, compreender o papel de uma abordagem sociológica na Estrutura, quando analisamos as relações entre os objetivos descritivo e explicativo que estruturam o modelo de ciência exposto no livro. Grosso modo, à história é atribuída a função de descrever o desenvolvimento das ciências ao longo do tempo, cabendo à sociologia apresentar os mecanismos que explicam tal padrão de desenvolvimento histórico.

As seções seguintes discutem as duas funções explicativas principais que podem ser atribuídas à sociologia na Estrutura. Em primeiro lugar, há um paralelismo entre as formas de prática científica com as mudanças de atitudes dos cientistas e as formas de organização da comunidade científica. A transição para a ciência madura, por exemplo, envolve a dissolução das antigas divisões entre as escolas e uma postura mais dogmática dos pesquisadores. O segundo elemento de caráter sociológico advém da explicação de Kuhn sobre formação de consenso. Para ele, o consenso racional entre cientistas não pode ser explicado como resultado da aplicação pura e descontextualizada de critérios de escolha. A convergência da comunidade é causada, em vez disso, por uma série de mecanismos sociais (nos quais têm lugar os valores epistêmicos).

\section{A sociologia na Estrutura}

O caminho de Kuhn até a filosofia foi bastante tortuoso. Sua formação acadêmica original, da graduação ao doutorado, deu-se toda na área de física. Ao final desse período, entretanto, Kuhn decidiu se dedicar à filosofia, a fim compreender melhor os fundamentos da ciência. Esta transição, contudo, não se

\footnotetext{
${ }^{3}$ Mas não totalmente, é preciso ressaltar: a história tem também muitas vezes na Estrutura um papel explicativo importante, como na compreensão dos fatores responsáveis pela eclosão de crises e pela resolução de controvérsias.
} 
deu de maneira imediata: antes de passar à filosofia, Kuhn dedicou mais de uma década ao estudo da história da ciência, acreditando que um conhecimento aprofundado da área seria fundamental para lhe dar uma visão mais fiel da ciência, quando comparado com as teorias filosóficas então populares. Foi apenas no final da década de 1950, e em particular com a publicação da Estrutura, em 1962, que Kuhn deu seu passo definitivo em direção à filosofia. ${ }^{4}$

O período de transição entre o fim do doutorado e a publicação da Estrutura, no qual se dedicou principalmente à história da ciência, foi aquele também no qual Kuhn tomou contato com outras áreas das ciências humanas, em particular com a sociologia e a psicologia. Mas para aqueles que desejam entender a influência resultante do contato com a sociologia da ciência para a Estrutura, a situação é desapontadora. Quase não há citações de trabalhos em sociologia da ciência no livro - situação que contrasta com as inúmeras menções a trabalhos em história da ciência e até mesmo em psicologia. Segundo Wray (2015), Kuhn "cita apenas uma fonte em sociologia da ciência na primeira edição de Estrutura (ou seja, menos de 1\%), 'Resistance by Scientists to Scientific Discovery', de Bernard Barber, um artigo publicado na Science" (p. 170).

Além da escassez de fontes da tradição sociológica, surpreende a falta de discussões teóricas sobre o tema. As possíveis conexões metodológicas da Estrutura com a sociologia não são abordadas por Kuhn no livro. ${ }^{5}$ Os diversos textos em que Kuhn narra essa etapa de sua formação intelectual tampouco contribuem para esclarecer essa questão (1962; 1977c; 1997). Também não são frequentes as referências a trabalhos em sociologia da ciência em outros textos de Kuhn: além das breves observações no Posfácio à Estrutura, sua única discussão mais extensa

\footnotetext{
${ }^{4} \mathrm{Na}$ Estrutura, Kuhn afirma que "com exceção de alguns artigos, este ensaio é a primeira de minhas publicações na qual essas preocupações iniciais são dominantes" (1962, p. 10). Para uma visão sobre sua produção anterior à Estrutura e sobre a relação desses trabalhos com seu principal livro, ver a introdução à coletânea de artigos $A$ tensão essencial (1977a) e a entrevista contida em $O$ caminho desde a Estrutura (1997). Para uma reconstrução detalhada da formação intelectual de Kuhn, ver Hufbauer (2012).

${ }^{5}$ A segunda edição da Estrutura traz um posfácio no qual são discutidas questões metodológicas sobre a identificação das comunidades científicas. No entanto, mesmo aí a sociologia se limita a um papel secundário, de fornecer instrumentos para a aplicação das teses de Kuhn à história da ciência. Como procuro mostrar aqui, a sociologia possui na verdade uma função mais fundamental na Estrutura que não é explicitamente tratada por Kuhn: a de explicar as mudanças de organização da comunidade científica e a formação de consenso.
} 
sobre trabalhos em sociologia encontra-se em um artigo do final da década de 1960 sobre a história da ciência (1968). ${ }^{6}$

A situação tem um quê de paradoxal: a Estrutura quase não fala sobre a sociologia da ciência; ainda assim, o livro teve historicamente uma influência considerável neste campo, servindo de marco teórico para diversas correntes dentro da sociologia da ciência. "Com tão poucas citações a fontes na sociologia da ciência", observa Wray (2015), "é algo surpreendente que o livro tenha influenciado tão profundamente os desenvolvimentos posteriores nesse campo" (p. 170).

A falta de menções e discussões sobre sociologia da ciência na Estrutura é facilmente explicável por uma série de fatores. A começar pela estrutura enxuta do livro como um todo. Tendo sido pensado inicialmente como um verbete sobre revoluções científicas para a Enciclopédia Internacional da Ciência Unificada, o texto manteve até o final seu caráter bastante conciso. ${ }^{7}$ O próprio Kuhn, no Prefácio, alertava sobre a "forma extremamente condensada e esquemática" que suas concepções recebiam no livro (1962, p. 13).

Outra razão para as poucas referências dirigidas à sociologia é a opção feita por Kuhn de enfatizar os elementos cognitivos envolvidos no desenvolvimento científico. Exceto por algumas breves considerações sobre a influência de aspectos biográficos e sociais na resolução de controvérsias científicas, a abordagem historiográfica adotada na Estrutura é preponderantemente internalista (Kuhn, 1983). ${ }^{8}$

Por último, parte da explicação para a ausência de discussões sobre sociologia da ciência talvez se deva ao próprio caráter incipiente dessa disciplina

\footnotetext{
${ }^{6}$ Sobre as interações de Kuhn com sociólogos da ciência, como Merton e Barber, ver Wray (2015, sec. 12.3).

7 A Enciclopédia Internacional da Ciência Unificada foi pensada como a culminação do projeto positivista. Por que teriam eles, então, chamado Kuhn, visto por muito tempo como o responsável pela morte do positivismo lógico, para contribuir com a enciclopédia? Durante muito tempo, o convite de Carnap foi visto como um trágico erro, fruto de sua incompreensão das novidades propostas por Kuhn. Desde a década de 1990, porém, as relações de Kuhn com o círculo positivista e suas divergências teóricas têm sido reavaliadas, suscitando inúmeros debates. Ver, por exemplo, Irzik \& Grünberg (1995); de Oliveira (2007); Uebel (2011); de Oliveira (2015); Tsou (2015)

${ }^{8}$ A caracterização da Estrutura como um trabalho internalista é uma simplificação grosseira (ainda que, para os propósitos em questão, sirva para destacar a preocupação com aspectos cognitivos, como teorias e resultados experimentais, mais do que com os contextos culturais e históricos). Para Kuhn, os valores da ciência são compartilhados pela comunidade; ao mesmo tempo, sua natureza baseada em exemplos abre espaço para divergências na aplicação destes valores pelos cientistas em casos reais. A natureza comunitária, mas não determinística, desses critérios de escolha acaba por implodir a distinção estrita entre fatores internos e externos. Ver Kuhn $(1977 b, 1983)$ e também Pirozelli (2019).
} 
(Daston, 2015). Tendo tomado contato com a história e a sociologia da ciência numa época em que estas disciplinas começavam a se institucionalizar, a produção inicial de Kuhn foi inevitavelmente marcada pelo uso bastante livre dos textos e conceitos encontrados em tais campos. Não havendo ainda uma tradição acadêmica consolidada naquele momento, suas relações com a sociologia só poderiam ser inevitavelmente abertas.

\section{A relação entre filosofia e sociologia}

A falta de discussões e menções à sociologia da ciência, assim como a ausência na Estrutura de discussões sobre temas tradicionalmente relacionados a esta disciplina - tais como a relação entre ciência e sociedade, a estrutura das comunidades científicas e o papel de determinantes sociais para o desenvolvimento científico -, podem dar a impressão de que a sociologia possuiria um papel secundário no projeto de Kuhn. Não fosse assim, poderíamos pensar, os temas e autores da sociologia seriam abordados de maneira explícita e pormenorizada.

Considerar a abordagem da Estrutura como fundamentalmente sociológica pode soar, desse modo, exagerado, quando não simplesmente despropositado. 0 próprio Kuhn, afinal, considerava a Estrutura como um trabalho de filosofia (1962, Prefácio). ${ }^{9}$ Em certo sentido, a avaliação não deixa de estar correta. A Estrutura é inegavelmente uma obra de filosofia: há um uso amplo de conceitos e temas filosóficos, como a noção de "incomensurabilidade" e a tese da contaminação teórica da observação. Mais importante ainda, o livro tem como objetivo principal responder a um problema filosófico clássico: o que é e como se produz conhecimento científico.

O que permite insistir, então, no caráter sociológico da Estrutura, dada a ausência de maiores referências e discussões sobre o tema na obra, e seu objetivo eminentemente filosófico? Acredito que o caráter sociológico da Estrutura pode ser

\footnotetext{
${ }^{9}$ A natureza do trabalho de Kuhn foi motivo frequente de discussões. Em um primeiro momento, filósofos como Popper e Lakatos consideraram a Estrutura como um trabalho de história da ciência (ver Lakatos \& Musgrave, 1970). Bird (2000), por sua vez, enxerga a Estrutura como um trabalho de meta-história. A maior parte dos autores, porém, tende a ver a obra de Kuhn como pertencente ao campo da filosofia da ciência.
} 
entendido quando deixamos em segundo plano a preocupação com as evidências textuais, e consideramos os objetivos gerais da obra.

O intuito de Kuhn na Estrutura é entender como a ciência se desenvolve ao longo do tempo. Tal questão, entretanto, comporta um caráter duplo, parte descritivo, parte normativo (Bird, 2000, p. 29). Do lado descritivo, Kuhn procura encontrar regularidades na história da ciência, como o surgimento de consensos, as mudanças de teorias e a proliferação de especialidades. Do lado normativo, ele busca identificar os aspectos da atividade científica que dão conta desse funcionamento específico. Em resumo, as duas perguntas que Kuhn visa responder na Estrutura são, respectivamente: "como a ciência se desenvolve ao longo do tempo?" e "por que a ciência se desenvolve desse modo?".

É pela ligação entre estas duas questões que o objetivo filosófico da Estrutura se liga a uma análise sociológica da ciência. A questão de "como a ciência se desenvolve ao longo do tempo?", de natureza descritiva, é respondida por Kuhn por meio de análises históricas. A resposta à segunda questão - "por que a ciência se desenvolve desse modo?" - , de caráter normativo, é respondida, em vez disso, por meio de uma teoria das comunidades científicas. Em outras palavras, a explicação de Kuhn sobre por que o desenvolvimento histórico da ciência segue determinado padrão - aquisição de paradigma, ciência normal, revolução, etc. é uma explicação de caráter sociológico. Isto é o que permite afirmar que a abordagem da Estrutura é essencialmente sociológica, ainda que seu interesse último seja dar conta de um problema filosófico geral. Como escreve Wray (2015), "embora fosse uma filosofia da ciência que Kuhn pretendia desenvolver em a Estrutura, a sociologia da ciência foi fundamental para seu projeto" (p. 174).

Em diversos momentos, o próprio Kuhn reconhece a natureza sociológica de seu projeto. Ele afirma, por exemplo, que "alguns dos princípios empregados em minha explicação da ciência são irredutivelmente sociológicos" (1970b, p. 164). Em outro momento, define os elementos de sua abordagem como "quase-sociológicos" (1997, p. 372), e descreve seu trabalho como "profundamente sociológico, mas não a ponto de permitir separar esse tema da epistemologia" (1977c, p. 21). Revisitando seu livro duas décadas depois, Kuhn explica que suas "preocupações, tanto na Estrutura quanto em outros lugares, foram de fato sociológicas, mas 
também foram inseparavelmente cognitivas ou epistêmicas" (1983, p. 28). ${ }^{10}$ Segundo ele,

a Estrutura é sociológica na medida em que enfatiza a existência de comunidades científicas, insiste que elas sejam vistas como produtoras de um produto especial, o conhecimento científico, e sugere que a natureza desse produto pode ser entendida em termos do que é especial na formação e valores desses grupos (1983, p. 28).

Em suma, os padrões de desenvolvimento da ciência identificados na história são explicados na Estrutura por meio de uma sociologia das comunidades científicas. Isso ocorre de duas maneiras principais. Em primeiro lugar, as transições entre as formas de atividade científica (como ciência normal e extraordinária) dependem de como se organizam as comunidades e das disposições comportamentais dos cientistas. Em segundo lugar, a natureza não determinística dos critérios de escolha demanda uma explicação da formação racional de consenso no nível da comunidade. A análise sociológica, assim, é o que permite tanto caracterizar as formas de atividade científica (escola, ciência normal, ciência extraordinária), como explicar a formação de consenso da comunidade - elementos centrais para explicar o padrão de desenvolvimento da ciência ao longo do tempo.

\section{Desenvolvimento científico}

A primeira forma de explicação sociológica se dá em relação ao padrão de desenvolvimento histórico das ciências. Como dissemos, um dos componentes da Estrutura é uma análise descritiva da história da ciência: para Kuhn, seria possível encontrar um padrão típico na forma como as ciências se desenvolvem ao longo do tempo. Ainda que o título do livro fale em "revoluções científicas", o objetivo de Kuhn é certamente mais amplo - o enfoque nas revoluções científicas se deve ao caráter não cumulativo desses eventos, que Kuhn procurou destacar.

10 Wray (2015) menciona ainda uma carta de Kuhn a Charles Morris, o editor da Enciclopédia Internacional da Ciência Unificada, na qual afirma que seu "problema básico é sociológico, uma vez que [...] qualquer teoria que perdure deve ser inserida em [um] grupo profissional" (p. 174, n. 14). 
O elemento norteador da análise histórica de Kuhn é a noção de "paradigma". ${ }^{11}$ Antes do estabelecimento que uma área de pesquisa se estabeleça como uma ciência propriamente dita, um mesmo conjunto de fenômenos é estudado por diversos grupos independentes e rivais, que Kuhn chama de "escolas". Cada um desses grupos se ocupa de refutar as posições adversárias e demonstrar a superioridade de sua própria perspectiva. Em determinado momento - ao menos para aqueles campos que vieram a se constituir como ciências - uma dessas teorias vence a disputa; isto é, passa a ser aceita pelos membros das diferentes escolas, que se organizam então em torno de uma mesma abordagem. Com a unificação da comunidade, os cientistas passam a explorar e desenvolver todo o potencial da nova abordagem - não mais em busca de prová-la ou refutá-la, mas empregando-a como um instrumento fértil para a solução de novos problemas. Daí a noção de "paradigma" como modelo de prática científica.

A aceitação de um paradigma não significa que a teoria seja capaz de solucionar todo e qualquer tipo de problema. Pelo contrário, a falta de adequação empírica e as dificuldades no âmbito teórico são o motor da pesquisa científica (daí a ideia de "ciência normal", como sendo aquela que os cientistas praticam a maior parte do tempo). Na maior parte das vezes, os quebra-cabeças, como são chamados por Kuhn, são resolvidos com o emprego do paradigma vigente. Às vezes, porém, as soluções desses problemas podem se mostrar mais difíceis, e a ausência de uma solução adequada pode acabar por gerar uma sensação de crise dentro da comunidade. Nesse momento, os compromissos profissionais se tornam mais frágeis, e o paradigma, mais nebuloso, levando à articulação de abordagens alternativas. Caso a comunidade escolha um novo paradigma, ocorre uma revolução científica. Os compromissos anteriores são reavaliados e uma nova tradição de ciência normal emerge.

Essa é, bastante sucintamente, a dinâmica do desenvolvimento das ciências descrita por Kuhn na Estrutura. Até aqui, porém, temos somente um retrato histórico do avanço das ciências. Esse, como dissemos, é o componente descritivo presente

\footnotetext{
${ }^{11}$ Como se sabe, o termo está entre os mais complexos da obra de Kuhn. Após uma série de críticas pelo uso elástico do termo na Estrutura, Kuhn (1970a) elencou dois sentidos que considerava fundamentais ao conceito. A partir daí, contudo, passou a empregar cada vez menos a noção de paradigma, voltando a utilizar a noção mais tradicional de "teoria". Meu objetivo aqui não é adentrar nessa discussão; por isso, tomo "paradigma" em seu sentido principal, que é aquele de "exemplar".
} 
na Estrutura. O modelo de Kuhn, contudo, comporta também um aspecto normativo, que visa explicar as razões para a existência desse padrão de desenvolvimento na ciência. Esse é o primeiro aspecto marcadamente sociológico da abordagem encontrada na Estrutura.

Para Kuhn, há um paralelo entre as etapas do desenvolvimento teórico com as atitudes dos cientistas e a estrutura da comunidade. $O$ tipo de ciência praticada pelos cientistas é explicada tanto pela estrutura da comunidade, como pelas disposições dos cientistas frente à pesquisa. Esse paralelo se dá em todas as transições delineadas na Estrutura, mas que podemos ilustrar com a passagem da ciência imatura para a ciência madura.

A rota para a ciência envolve, para Kuhn, a aquisição de um primeiro paradigma pela comunidade, que faz encerrar a divisão existente entre as várias escolas rivais. Isso ocorre, porque, de algum modo, os cientistas envolvidos se convencem da superioridade de uma das abordagens em jogo. A consequência disso, no nível social, é uma mudança na organização comunitária, com a formação - primeiro de maneira informal, e depois institucionalizada - de um grupo coeso em torno de uma única teoria.

Essa mudança na estrutura da comunidade está ligada também a uma mudança comportamental. Na fase pré-paradigmática, o objetivo principal dos cientistas é justificar a própria teoria e refutar as posições adversárias. Isso implica um grande esforço de argumentação direcionado a outras teorias e uma tentativa constante de fundamentar as próprias posições. Ao mesmo tempo, não tendo um paradigma que direcione as investigações, as observações feitas tendem a ser realizadas de maneira superficial e não sistemática.

Com a criação de um consenso comunitário, o comportamento dos cientistas muda radicalmente. A teoria vencedora passa a ser tomada como um "paradigma", em sentido estrito - isto é, como um modelo de prática científica a ser melhor articulado. Sendo assim, não há mais necessidade por parte dos membros da comunidade de justificar o paradigma. O esforço passa a ser voltado exclusivamente a "refinar, ampliar e articular um paradigma que já existe" (1962, p. 160). As observações e experimentos tornam-se altamente especializados, buscando revelar aspectos recônditos da natureza. 
Vê-se aqui, para o caso da transição para a ciência anormal, o paralelo entre o padrão de desenvolvimento científico e a organização social da ciência, e como o primeiro é explicado pela segunda. No nível conceitual, ciência normal nada mais é do que o tipo de ciência caracterizado pela exploração exaustiva de um paradigma, que resulta numa adição cumulativa de conhecimento. Para que a ciência normal possa ocorrer, entretanto, são necessárias duas coisas: pelo lado da organização comunitária, um consenso relativo (não necessariamente explícito) de seus membros quanto aos paradigmas daquele campo; e pelo lado das disposições comportamentais, um esforço por parte dos cientistas de tentar articular os paradigmas aceitos. São esses dois elementos de caráter sociológico que explicam a capacidade da ciência normal de produzir conhecimento - dado que os cientistas podem assumir uma série de informações e explorar as questões mais técnicas e seu caráter cumulativo - pois as novas realizações são vistas como desdobramentos do paradigma. Além disso, os aspectos conceitual e social da ciência se retroalimentam: as realizações do paradigma reforçam as atitudes acríticas dos cientistas, assim como a estrutura da comunidade garante a existência desse tipo de pesquisa, reproduzindo o consenso sobre a teoria vigente.

Paralelos semelhantes existem também nas demais fases da ciência. Algumas dificuldades enfrentadas pelo paradigma podem, por exemplo, gerar um sentimento de crise na comunidade (Kuhn, 1962, cap. 6). A crise tem, primeiro um caráter psicológico - a quebra de expectativa em relação ao paradigma - , que leva então a alterações na disposição dos cientistas, como o relaxamento dos pressupostos do paradigma e a tentação de explorar abordagens novas. Com o agravamento da crise, a própria comunidade se reorganiza, passando a se dividir em grupos menores, de maneira semelhante à ciência imatura. Apenas quando um novo paradigma é aceito, a comunidade volta a se organizar em torno de uma única teoria, e os cientistas voltam a tomá-la como pressuposto da sua prática.

Em resumo, há uma conexão entre desenvolvimento teórico e funcionamento comunitário. As atitudes dos cientistas e a forma como se relacionam explicam o tipo de ciência praticado em cada uma das etapas do desenvolvimento científico. A ciência normal, por exemplo, está relacionada ao consenso comunitário e à aceitação ampla do paradigma, enquanto a ciência revolucionária é caracterizada pela fragmentação da comunidade e o relaxamento dos compromissos comunitários. 


\section{Formação de consenso}

O segundo componente de caráter marcadamente sociológico da Estrutura refere-se à formação de consenso. Uma das principais ideias do livro é a rejeição do pressuposto de que debates científicos são resolvidos por meio da aplicação de regras metodológicas ("a insuficiência das diretrizes metodológicas para ditarem, por si só, uma única conclusão substantiva para várias espécies de questões científicas" (1962, p. 22)). Para Kuhn, cientistas podem aplicar os mesmos valores epistêmicos e ainda assim chegar a conclusões distintas sobre qual teoria adotar.

Ocorre que, se critérios de escolha podem ser aplicados distintamente pelos cientistas, então a resposta sobre o que leva um cientista a escolher uma teoria não pode servir para explicar como se forma o consenso. O problema da escolha de teorias é separado por Kuhn em duas questões distintas: uma sobre a escolha das teorias feita pelos indivíduos e outra sobre a formação de consenso comunitário

Em relação ao primeiro desses problemas, a resposta de Kuhn não se distingue da visão tradicional, segundo a qual cientistas escolheriam teorias a partir de valores como precisão, simplicidade, consistência, abrangência e fecundidade (1977b). A inovação de Kuhn está em sua abordagem ao problema da formação de consensos científicos. O surgimento do consenso na ciência é explicado, por ele, por meio de uma série de mecanismos sociológicos. ${ }^{12}$

São três os mecanismos principais a promover o consenso em um grupo de cientistas: a pedagogia científica, o mecanismo de onda e a reestruturação da comunidade científica. A pedagogia científica é o que explica que, na prática, cientistas tenham avaliações similares. Os processos de socialização e iniciação profissional homogeneizam as práticas dos diversos membros. Com isso, reduzem as oportunidades de desacordo, facilitando o surgimento de consensos e garantindo a estabilidade durante os períodos de ciência normal.

O segundo desses mecanismos, que D'Agostino (2010) chama de "mecanismo de onda", opera nos momentos de desacordo da comunidade. Nesses

\footnotetext{
12 Para ser mais preciso, poderíamos chamá-los de mecanismos sócio-epistêmicos, dado que os valores utilizados para a escolha são valores epistêmicos (voltados a encontrar teorias melhores), e que o resultado dessas interações sociais é a produção de conhecimento (Wray, 2011).
} 
casos, o conhecimento é produzido por meio de um convencimento progressivo dos cientistas em direção a uma única teoria. Esquematicamente, o processo se dá da seguinte maneira. Convictos da superioridade de uma nova teoria, alguns poucos cientistas pioneiros decidem adotá-la. Enquanto a maioria dos cientistas permanece fiel à abordagem mais antiga, os adeptos da nova teoria começam a trabalhar sob esta nova abordagem. Se bem-sucedidos, produzem argumentos e evidências que dão apoio à nova teoria. Com isso, outros cientistas da comunidade decidem adotar a abordagem mais recente. Com o tempo, o número de adeptos da nova teoria cresce, vindo a gerar um novo consenso. ${ }^{13}$

Muitas vezes, porém, esse processo de convencimento gradual mostra-se incapaz de gerar uma adesão completa dos membros da comunidade. Nesse caso, a controvérsia só se encerra com a reestruturação da comunidade - o terceiro mecanismo em jogo. Essa reestruturação social pode ocorrer de duas maneiras pela marginalização dos membros resistentes (Kuhn, 1962, p. 202) ou pela criação de novas especialidades (Kuhn, 1991, 1992). Se apenas alguns poucos membros permanecerem fiéis à antiga abordagem, estes costumam ser simplesmente postos de lado pela comunidade: deixam de participar dos debates, publicar em periódicos conceituados, participar de congressos, receber citações, etc. Quando o desacordo é mais amplo, pode ocorrer em vez disso a divisão da comunidade e a formação de uma nova especialidade. A comunidade então se fragmenta em disciplinas autônomas, cada uma delas responsável por um conjunto delimitado de problemas (ver especialmente Wray, 2011, Parte II).

Esses são os tipos de mecanismo social que explicam, segundo Kuhn, a formação de consenso. A pedagogia científica reduz o campo de divergência potencial; o mecanismo de onda permite a ampliação do grupo original por meio da produção de novas realizações científicas, que convencem outros membros da comunidade; e, quando o mecanismo de onda se mostra insuficiente, a reestruturação comunitária atua para excluir os membros resistentes ou, quando

\footnotetext{
13 O mecanismo de onda é, na verdade, mais complexo que a descrição exposta acima. Embora compartilhem os mesmos compromissos, existem sempre divergências latentes entre as formas de praticar ciência de cada indivíduo (um consenso "na superfície" (shallow), de resultados, e não quanto aos fundamentos profundos D'Agostino (2005)). Nos momentos de crise, quando os pressupostos do paradigma se afrouxam, essas divergências vêm à tona. A implicação disso é que cientistas de uma mesma comunidade podem vir a adotar uma nova teoria em momentos diferentes e por diferentes motivos; o que faz com que o processo de mudança de adesão varie para cada comunidade particular (Plastino, 2019).
} 
estes forem em número relevante, dividir a comunidade de forma a espelhar a separação conceitual subjacente.

Em suma: se, para Kuhn, a escolha de uma teoria por um cientista pode ser explicada pelo uso de valores epistêmicos (como precisão e consistência), a aceitação de uma mesma teoria pela comunidade é explicada por meio de padrões específicos de interação entre os indivíduos da comunidade - como são educados e socializados, como produzem novas evidências e apresentam argumentos, e como se reorganizam em grupos menores. Uma explicação de natureza sociológica, portanto.

\section{Considerações finais}

A proximidade entre a Estrutura e a sociologia da ciência são bastante conhecidas, mas geralmente pouco compreendidas. Parte da dificuldade, como visto anteriormente, deriva da concisão e interdisciplinaridade da obra de Kuhn, assim como da ausência de discussões sobre essa questão no texto.

Contudo, se a Estrutura não se filia claramente a uma tradição de pesquisa em sociologia, oferece, em lugar disso, uma compreensão sociológica do desenvolvimento científico. Neste artigo, procurei discutir os dois elementos que permitem considerar a abordagem proposta por Kuhn como essencialmente sociológica. Os padrões de mudança da ciência no tempo são explicados tanto pela organização da comunidade científica e disposições comportamentais dos cientistas, como pela maneira como são resolvidas as controvérsias científicas.

Por último, é preciso ressaltar que tal perspectiva sociológica não desconsidera o caráter epistêmico da ciência. Valores epistêmicos, tais como simplicidade, precisão e abrangência, são elementos centrais na prática científica, que estão envolvidas nas escolhas de teorias e nas decisões de pesquisa dos cientistas. Esses valores são particularmente importantes para explicar tanto a existência de desacordos durante os períodos de ciência extraordinária, como a formação de consenso que muitas vezes se segue, seja em episódios de revolução como de especialização. Por esse motivo, a abordagem de Kuhn na Estrutura mostra-se uma fonte rica de indagações e ideias para as investigações atuais em filosofia da ciência e, especialmente, para o campo da epistemologia social. 


\section{Agradecimentos}

Agradeço ao professor Caetano Ernesto Plastion pelos valiosos comentários à primeira versão deste artigo. Este trabalho foi executado no Centro de Inteligência Artificial (C4AI-USP) com apoio da Fundação de Apoio à Pesquisa do Estado de São Paulo (processo FAPESP \#2019/07665-4) e da IBM Corporation.

\section{Referências}

ABBOTT, A. Structure as Cited, Structure as Read. In: R. J. Richards; L. Daston (eds.), Kuhn's Structure of Scientific Revolutions at Fifty: Reflections on a Science Classic. University of Chicago Press, 2016, p. 167-81.

BARNES, B.; BLOOR, D. Relativism, Rationalism and the Sociology of Knowledge. Rationality and Relativism. In: M. Hollis; S. Lukes (eds.), Rationality and Relativism. Blackwell, 1982, p. 21-47.

BARNES, B.; BLOOR, D.; HENRY, J. Scientific Knowledge: A Sociological Analysis. A\&C Black, 1996.

BIRD, A. Thomas Kuhn. Acumen Publishing, 2000.

BIRD, A. Kuhn's Wrong Turning. Studies in History and Philosophy of Science Part A, v. 33, n. 3, 2002, p. 443-63.

COLE, J. R.; ZUCKERMAN, H. The Emergence of a Scientific Specialty: The Self-Exemplifying Case of the Sociology of Science. In: The Idea of Social Structure. Routledge, 2017, p. 13974.

DASTON, L. Science, History of. In: James D. Wright (ed.), International Encyclopedia of the Social and Behavioral Sciences, 2015, p. 241-47.

D'AGOSTINO, F. Kuhn's Risk-Spreading Argument and the Organization of Scientific Communities. Episteme, v. 1, n. 3, 2005, p. 201-09.

D'AGOSTINO, F. Naturalizing Epistemology: Thomas Kuhn and the 'Essential Tension'. Palgrave Macmillan, 2010.

de OLIVEIRA, J. C. P. Carnap, Kuhn, and Revisionism: On the Publication of Structure in Encyclopedia. Journal for General Philosophy of Science / Zeitschrift für Allgemeine Wissenschaftstheorie, v. 38, n. 1, 2007, p. 147-57.

de Oliveira, J. C. P. Carnap, Kuhn, and the History of Science: A Reply to Thomas Uebel. Journal for General Philosophy of Science / Zeitschrift für Allgemeine Wissenschaftstheorie, v. 46, n. 1, 2015, p. 215-23.

GAVROGLU, K. An Episode from the History of History and Philosophy of Science: The Phenomenal Publishing Success of Kuhn's Structure. In: A. Blum; K. Gavroglu; C. Joas; J. 
Renn (eds.), Shifting Paradigms: Thomas S. Kuhn and the History of Science. Edition Open Access, 2016, p. 43-70.

HUFBAUER, K. From Student of Physics to Historian of Science: Thomas Kuhn's Education and Early Career, 1940-1958. Physics in Perspective, v. 14, n. 4, 2012, p. 421-70.

IRZIK, G.; GRÜNBERG, T. Carnap and Kuhn: Arch Enemies or Close Allies? The British Journal for the Philosophy of Science, v. 46, n. 3, 1995, p. 285-307.

KAISER, D. Thomas Kuhn and the Psychology of Scientific Revolutions. In: R. J. Richards; L. Daston (eds.), Kuhn's Structure of Scientific Revolutions at Fifty: Reflections on a Science Classic. University of Chicago Press, 2016, p. 71-95.

KUHN, T. S. A estruturas das revoluções científicas. São Paulo: Perspectiva, 2007. [1962]

KUHN, T. S. A história da ciência. In: $A$ tensão essencial. São Paulo: Editora UNESP, 2011. [1968].

KUHN, T. S. Posfácio. In: $A$ estruturas das revoluções científicas. São Paulo: Perspectiva, 2007. [1970a]

KUHN, T. S. Reflections on my Critics. In: The Road since Structure. University of Chicago Press, 2000. [1970b]

KUHN, T. S. $A$ tensão essencial. São Paulo: Editora UNESP, 2011. [1977a]

KUHN, T. S. Objetividade, juízo de valor e escolha de teoria. In: $A$ tensão essencial. São Paulo: Editora UNESP, 2011 [1977b]

KUHN, T. S. Apresentação. In: A tensão essencial. São Paulo: Editora UNESP, 2011. [1977c]

KUHN, T. S. Reflections on Receiving the John Desmond Bernal Award. 4S Review, v. 1, n. 4, 1983, p. 26-30.

KUHN, T. S. O caminho desde $A$ estrutura. In: $O$ caminho desde A estrutura. São Paulo: Editora UNESP, 2006. [1991]

KUHN, T. S. O problema com a filosofia histórica da ciência. In: $O$ caminho desde A estrutura. São Paulo: Editora UNESP, 2006. [1992]

KUHN, T. S. Um debate com Thomas Kuhn. In: $O$ caminho desde A estrutura. São Paulo: Editora UNESP, 2006. [1997]

LAKATOS, I.; MUSGRAVE, A. Criticism and the Growth of Knowledge. Cambridge University Press, 1970.

MLADENOVIĆ, B. 'Muckraking in History': The Role of the History of Science in Kuhn's Philosophy". Perspectives on Science, vol. 15, no. 3, 2007, p. 261-94.

PIROZELLI, P. Thomas Kuhn's Theory of Rationality. Manuscrito, v. 42, n. 3, 2019, p. 1-46.

PIROZELLI, P. From Empirical Evidence to First Principles. Veritas (Porto Alegre), v. 65, n. 3, 2020, p. 1-10. 
PLASTINO, C. E. Crise e Formação de Consenso na Ciência Segundo Kuhn. Revista Enunciação, v. 4, n. 2, 2019, p. 148-58.

SCHEFFLER, I. Science and Subjectivity. 2ed. Hackett Publishing Company, 1982.

SHAPERE, D. The Structure of Scientific Revolutions. Philosophical Review, v. 73, n. 3, 1964, p. 383-94.

SHAPIN, S. Discipline and Bounding: The History and Sociology of Science as Seen Through the Externalism-Internalism Debate. History of science, v. 30, n. 4, 1992, p. 333-69.

TSOU, J. Y. Reconsidering the Carnap-Kuhn Connection. In: W. J. Devlin; A. Bokulich (eds.), Kuhn's Structure of Scientific Revolutions - 50 Years on. Springer, 2015, p. 51-69.

UEBEL, T. Carnap and Kuhn: On the Relation between the Logic of Science and the History of Science. Journal for General Philosophy of Science / Zeitschrift für Allgemeine Wissenschaftstheorie, v. 42, n. 1, 2011, p. 129-40.

WRAY, K. B. Kuhn's Evolutionary Social Epistemology. Cambridge University Press, 2011.

WRAY, K. B. Kuhn's Social Epistemology and the Sociology of Science. In: W. J. Devlin; A. Bokulich (eds.), Kuhn's Structure of Scientific Revolutions - 50 Years on. Springer, 2015, p. 167-83. 